\title{
Credal Dilemmas
}

\author{
SARah Moss \\ University of Michigan
}

Formal epistemologists traditionally model rational states of partial belief with probability measures, functions that map each proposition to a single real number. But many have recently rejected this model as excessively precise. Sometimes your evidence for a certain claim is unspecific. And many have argued that the rational response to unspecific evidence is to have credences that are imprecise, represented not by a single probability measure but by a set of measures. ${ }^{1}$ However, fans of imprecise credences face a formidable challenge, namely providing a decision theory that protects agents who follow it from forgoing sure money. Agents with imprecise credences seem doomed to act irrationally when faced with diachronic decision problems, where they are called to make decisions at earlier and later times. ${ }^{2}$

In this paper, I aim to respond to this challenge on behalf of imprecise credence fans. In fact, we have subtle and variegated intuitions about what actions are rational in various diachronic cases. Once we appreciate the complexity of these intuitions, we can see that diachronic cases are in fact evidence for the claim that rational agents can have imprecise credences. In $\S 1$, I briefly make the case for accepting that agents have imprecise credences. In $\$ 2$, I explain the case against imprecise credences in more detail. In $\S 3$, I investigate our intuitions about norms governing agents who are torn between different precise credal states. These agents face credal dilemmas, epistemic analogs of moral dilemmas. I argue that recognizing the strong similarities between moral and credal dilemmas is a desideratum for any theory of the latter. In $\S 4$, I describe our intuitions about diachronic norms governing agents in credal dilemmas. I argue that predicting these intuitions is a second desideratum of our theory. In $\S 5$, I use imprecise credences to model the doxastic states of agents facing credal dilemmas, and I defend a theory of credal dilemmas that satisfies both desiderata just described. In $\S 6$, I situate my arguments in the debate over whether we may represent rational agents as having imprecise credences, explaining why my $\S 5$ arguments constitute support for imprecise credence fans. Finally, I situate my arguments in the context of a general movement towards "time slice epistemology," according to which the fundamental norms of rationality are diachronic in nature.

Thanks to John Broome, Adam Elga, Jim Joyce, Susanna Rinard, Scott Sturgeon, and the University of Michigan Crop Circle for comments on earlier drafts of this paper. Thanks also to audiences at MIT, Oxford, Tufts, University of Vermont, the University of Michigan Ethics Discussion Group, and the 2012 Formal Epistemology Workshop for helpful discussion.

(c) 2014 Wiley Periodicals, Inc. 


\section{The Case For Imprecise Credences}

Suppose you see a stranger pulling objects out of a bag. He pulls out a tube of toothpaste, a live jellyfish, and another tube of toothpaste. As you are watching, he starts to pull out a fourth object. Elga (2010) uses this example to motivate the imprecise credence view. According to the fan of imprecise credences, you may not be able to say how likely you think it is that the fourth object will be a tube of toothpaste. In addition, your reluctance to have a settled opinion seems appropriate. At best, having some exact assessment of the likelihood of more toothpaste would be a foolhardy response to your unspecific evidence. To sum up the argument: intuitions about cases of unspecific evidence dictate that alternatives to precise credal states are sometimes actual, appropriate, or even required. Imprecise credence models enable us to respect these intuitions, namely by representing your opinions by a set of probability measures. Following van Fraassen (1990), let us call this set your representor. Having multiple probability measures in your representor may be the appropriate or required response to unspecific evidence. ${ }^{3}$

It is important to recognize that certain intuitions can be accommodated by precise credence models. For instance, you may sometimes have latitudinarian beliefs about your opinions, such as the belief that there is no particular credence that you are rationally bound to assign to the claim that more toothpaste comes next. Fans of precise credences can accommodate the intuition that latitudinarian second-order beliefs are sometimes actual, appropriate, or required. They may say that agents are rationally bound to have precise credences, while denying that there are particular precise credences that agents are rationally bound to have. The introduction of imprecise credences is motivated by the thought that rational first-order opinions may encompass multiple precise credal states, where simply ascribing latitudinarian second-order beliefs does not adequately capture this multiplicity. In other words, standard decision theorists cannot do justice to the intuition that rational opinions may be symmetrically related to multiple probability measures. By contrast, imprecise credence fans can easily recognize multiple probability measures in representing your opinions, by saying that each of the relevant measures is contained in your representor.

\section{The Case Against Imprecise Credences}

It is fair to say that decision theoretic concerns have been the biggest impediment to general acceptance of imprecise credences. Dorr (2010) objects that "there is no adequate account of the way unsharp credences should be manifested" in decision making. White (2010) criticizes candidate decision theories. The central thesis of Elga (2010) is that no decision theory for imprecise agents can accommodate basic intuitions about rational action. In particular, it is hard to say how imprecise agents should act in diachronic decision cases, when they are offered bets at earlier and later times.

For example, say I offer you a bet: if the stranger is about to pull out another tube of toothpaste, I give you ten dollars; otherwise, you give me nine. Then before 
you learn any relevant information, I offer you a second bet: if more toothpaste comes next, you give me nine dollars; otherwise, I give you ten. Suppose that in light of your unspecific evidence, you are torn between a wide range of credences about whether toothpaste comes next. Assuming standard decision theory, some but not all of those credences would recommend you take the first bet, and likewise for the second. Imprecise credence fans must have some theory about what actions are permissible when you face decisions like these, namely when different actions maximize expected utility according to different members of your representor.

Elga (2010) divides imprecise decision rules into three categories. Strict and global rules constrain imprecise agents to act like precise agents. ${ }^{4}$ Strict rules say that for any imprecise agent, there is a unique precise credal state such that the agent must evaluate all bets as she rationally would if she were in that state. Elga objects that strict decision rules undermine our motivation for accepting imprecise credences. Insofar as unspecific evidence intuitively precludes having precise credences, it also precludes acting as if you have precise credences. By contrast, global rules say that an agent may accept any bet sanctioned by some member of her representor without thereby having done anything irrational, as long as she has not already made decisions prohibited by that same representor member. Elga objects that according to global rules, different actions will be permissible for agents who share intrinsic properties. Elga argues that this is unacceptable, since whether you accepted some bet on a proposition should not constrain your opinions about that proposition, nor should it constrain the actions permissible for you as an agent with those opinions. $^{5}$

For sake of argument, let us grant that strict and global decision rules are unacceptable. Fans of imprecise credences may still endorse a third option: permissive decision rules. According to a permissive rule, you may perform an action without thereby having done anything irrational just in case that action is permissible according to some member of your representor. For example, rationality does not legislate your response to either of the toothpaste bets. Accepting and rejecting the first bet are both permissible, and likewise for the second bet. Permissivism seems like the most natural response when you are torn between accepting and declining a bet. Intuitively, if you are of two minds about a decision, rationality alone cannot break symmetries in your credal state. Each action must be at least as permissible as the other. Hence as long as some action is permissible, each will be permissible.

The problem is that permissive rules excuse apparently irrational behavior. For example, permissive rules entail that you may reject both toothpaste bets without thereby having done anything irrational. Opponents of imprecise credences protest: if you had accepted both bets, you would have gained one dollar, no matter what the stranger pulled out of his bag. Hence by the time you reject the second bet, you will have forgone sure money for nothing. And forgoing sure money seems irrational. Opponents of imprecise credences conclude: permissive decision rules are incorrect. There is no viable decision theory for imprecise agents.

This argument may cast doubt on whether rational agents can have imprecise credences at all. After all, standard decision theory has no problem predicting that it is impermissible for precise agents to reject both bets. If you do not learn any 
relevant information between rejecting the first bet and considering the second, you have the same credal state when you consider both bets. If rejecting the first bet maximizes expected utility according to that credal state, then so does accepting the second bet. ${ }^{6}$ In more generality, standard decision theory entails the following claim:

(DDB):

If accepting each of a pair of bets would guarantee you sure money, and you rejected the first and have not since learned anything, then you cannot rationally reject the second bet.

Furthermore, (DDB) entails our intuition that you should not forgo sure money in the toothpaste case. Hence standard decision theory entails our intuition about the toothpaste case, while permissive decision rules do not. To sum up: in the debate between Sharpies and Mushies, it appears that the score so far is $1-0$, Sharpies. ${ }^{7}$

\section{Moral Dilemmas and Credal Dilemmas}

The score is far from settled. So far we have explored our intuitions about one example. But we should be more careful about what intuitions we take as data for our theory of credal dilemmas. It is true that in many cases, it is intuitively bad to reject each of a pair of bets that guarantee sure money. Furthermore, when a case involving such bets is underdescribed, we naturally fill in the details for ourselves so that rejecting both bets seems bad. But it is not always intuitively bad to reject both bets, even when you do not get additional evidence between rejecting the first bet and considering the second. In fact, we can describe cases where it is intuitively permissible to reject each of a pair of bets that guarantee sure money.

Just imagine that you are torn between two very different options. In fact, you wish you could split yourself down the middle and try both. After agonizing over your predicament, you finally commit to one half of yourself over the other, forgoing benefits that your second half prefers. But after that, you have second thoughts. It is not that you get some relevant evidence. It is just that your second half prevails after all. Of course, now you regret what you did before. But as a rational agent, you are determined to ignore sunk costs. As you now identify with your second half, you act accordingly, forgoing benefits that your first half prefers. Broome (1999) vividly describes a case of this sort:

Suppose two careers are open to you: a career in the army and a good career as a priest. Suppose they are incommensurate in their goodness. Then choosing either would not be wrong. You have to choose without the guidance of reason, and suppose you choose the army: you commit yourself to the army career, and give up the chance of a good career in the church. In doing so you are doing nothing wrong. But then suppose another opportunity comes up to join the church, this time in much worse conditions. You now face a choice between the army or a much less good career as a priest. Suppose these two, also, are incommensurate. Choosing either would not be wrong. You have to choose without the guidance of reason...You might just change your mind between one decision and the next. Having chosen the army, you might decide that was a mistake, 
and make the best of a bad job by taking up the only church career that is still available. Then you would not have acted irrationally. Nor is it puzzling that you end up worse off than you could have been. (156-7)

Broome intends this case to illustrate that you may change which career you pursue as a result of having incommensurable values. But our judgments about the case do not essentially depend on your being torn between the army and the church for this reason. For instance, suppose that you want to choose your career on strictly utilitarian grounds, but your limited evidence does not settle whether the army or the church has a higher expected value in that sense. Then you must choose your career "without the guidance of reason," or more specifically, without the firm guidance of your evidence. It is possible that in this sort of case, you may be moved to prefer the army and then later moved in just the same way to prefer the church, repudiating your earlier decision and vowing to "make the best of a bad job" by accepting the best church career on offer.

For a second example of rational mind changing, suppose that your elderly mother must move in with family, either with you or with your sister in a distant city. There is a trusted psychologist who will soon make an expert recommendation about which living situation would make your mother happiest. From your perspective, the question seems impossible. There are many factors to consider, and nothing to decide the question. After agonizing, you conclude that your mother will likely end up being happiest with you. Just a few hours later, a friend offers you 5000 frequent flyer miles in exchange for five local bus tickets. But since your mother would enjoy using the bus to get around, it makes more sense for you to keep your tickets. The next morning, however, you start to feel differently. It is not that you have gotten relevant evidence. The question is just as intractable as before. It is just that you are having second thoughts about where your mother would be happiest. Of course, now you wish you had taken your friend up on the frequent flyer miles. By coincidence, another friend offers you six local bus tickets in exchange for 5000 miles. But since you figure that your mother will end up living with your sister, and since you plan on visiting them often, it makes more sense for you to keep your miles.

If you had first traded for the miles and then traded for the bus tickets, you would be one bus ticket ahead. But intuitively, your rejecting both trades does not make you irrational. In many cases where you are torn between credal states, you may naturally change your mind before settling on an action-guiding plan. In the case just described, losing out on a bus ticket is an unfortunate consequence of that behavior. But intuitively, this consequence is not a sign of your irrationality, just a sign of your divided state of opinion. To judge otherwise fails to recognize a simple and familiar way in which we can rationally change our minds.

To sum up so far: there are two ways for a decision to be difficult. Agents can be torn between multiple value functions, as in Broome's original example, or torn between credal states, as in the example of the elderly mother. The former yields a familiar variety of indecision. In our ordinary descriptions of moral dilemmas, we often mention values that recommend different actions. ${ }^{8}$ Such dilemmas constitute 
a host of additional examples where agents can rationally change their minds. Consider the student from Sartre (1946) who is torn between joining the Free French and helping his mother at home. Suppose he first elects to stay with his mother, but then has second thoughts. If he does eventually leave for the army, he is not irrational in virtue of having missed the earliest possible convoy. Similarly, you are not irrational when you change your order at a restaurant, or when you change careers after acquiring non-transferrable skills at your first job. Perhaps such reconsideration is best described as a change of heart, rather than a change of mind. The point is that while either sort of change may be unfortunate, neither is forbidden tout court. In both moral dilemmas and credal dilemmas, there are some cases where it is intuitively impermissible to reject good pairs of bets, i.e. pairs of bets that guarantee sure money. But in both sorts of dilemmas, there are also some cases where it is intuitively permissible to reject good pairs of bets. Taken together, these contrasting cases raise an important question: which intuitions should we vindicate in giving a theory of credal dilemmas? The upshot of reflecting on moral dilemmas is that our answer to this question should be guided by the following desideratum: our theory of credal dilemmas should mirror our theory of moral dilemmas.

It is not just that we have similar normative judgments about moral and credal dilemmas. In either case, your decision necessarily falls outside the purview of standard decision theory. It is often said that moral dilemmas seem to demand some sort of arbitrariness from an agent, and the same has been said for credal dilemmas: "it must be really inexplicable why an agent chooses" according to one representor member instead of another (Weatherson 2008, 13). In light of these similarities, we would need to have some positive reason motivating us to theorize differently about sources of the same sort of practical indecision.

In addition, it is often unclear that one can even distinguish sources of practical indecision as reflecting multiple credences rather than multiple values. For instance, changing your career may call to mind incommensurable values, but also different credences about what will make you and others most satisfied. It is not obvious that one can ultimately give solid grounds for attributing indecision to a multiplicity of values rather than a multiplicity of opinions about what is valuable. Conversely, it may be that credal dilemmas come about when an agent has incommensurable epistemic values. For instance, it may be that the strongest hypothesis supports one opinion while the simplest supports another, leaving the circumspect agent torn between those opinions. If radically different norms governed agents in credal and moral dilemmas, one would not expect that we as theorists would have such a hard time discriminating credence-related and value-related sources of practical indecision.

Williams (1965) famously argues that we ought not assimilate conflicts of belief and conflicts of desire:

(a) If I discover that two of my beliefs conflict, at least one of them, by that very fact, will tend to be weakened; but the discovery that two desires conflict has no tendency, in itself, to weaken either of them...(b) Suppose the conflict ends in a decision...The rejected belief cannot substantially survive this point, because to decide that a belief 
is untrue $i s$ to abandon, i.e., no longer to have, that belief, [while] a rejected desire, however, can, if not survive the point of decision, at least reappear on the other side of it on one or another guise. (119)

This passage nicely brings out why imprecise credences, rather than inconsistent beliefs, are the epistemic analog of incommensurable values. Being aware that multiple precise credal states are represented by your representor members does not have a tendency, in itself, to weaken any of them. In both moral and credal dilemmas, it is merely that some practical decision forces you to identify with one rather than the other. Furthermore, in just the same way that rejected desires remain live, so do rejected credal states. "Should I have taken that bet about the toothpaste? Is it really more likely than not that more toothpaste is next?" "Is my mother really better off with my sister? Or will she end up living here with me, after all?"

The arguments in this section yield a preliminary upshot for the debate over imprecise credences. In the moral dilemmas literature, a number of theories say that agents with incommensurable values may violate standard norms of rationality, say by rejecting good pairs of bets. This has prompted occasional skepticism about whether agents in fact have incommensurable values, but it has by no means settled the debate. In particular, it remains an open question whether we should aim to predict that rational agents cannot reject good pairs of bets. By comparison, it seems hasty to use diachronic cases to rule out analogous theories of credal dilemmas and thereby conclude that rational agents must have precise credal states.

\section{How Intuitions Should Inform our Theory of Credal Dilemmas}

If we can rationally reject good pairs of bets in moral dilemmas, we can rationally reject good pairs of bets in credal dilemmas. But should we use this as the premise of a modus ponens or modus tollens argument? Roughly speaking, Chang (1997b) opts for modus tollens. She describes a case where an agent loses money in virtue of having incommensurable values, and she concludes that "a pragmatic challenge to those who would oppose comparativism is to provide a well-motivated, non-ad-hoc account of how practical reason prohibits agents from becoming "merit pumps"” (11). But we need not follow Chang here. In short, there are two strategies for explaining the intuitions canvassed so far. Strategy A: we endorse a theory that entails (DDB). Our theory is incompatible with our intuitions about cases where it seems agents may reject good pairs of bets without learning, like the case of the elderly mother in $\$ 3$. But we explain away those intuitions by other means. Strategy $\mathrm{B}$ : we endorse a theory that does not entail (DDB). Our theory is compatible with our intuitions about cases where it seems agents may reject good pairs of bets. But we must find some alternative explanation for our intuitions about cases where it seems agents may not reject good pairs of bets, like the cases described by Elga (2010) and Chang (1997b). We cannot use (DDB) to explain those intuitions.

Standard decision theory commits us to Strategy A. But Strategy B seems preferable, ceteris paribus. Strategy A requires that we give an error theory of some ordinary judgments. Strategy B merely requires that we supplement our theory before 
predicting ordinary judgments. Strategy B allows that subtle differences between cases may settle whether agents may reject good pairs of bets without learning.

Strategy B is even more compelling in light of the contours of the normative intuitions we are aiming to explain. It is not just that we say that rejecting good pairs of bets is sometimes bad and sometimes okay. Our judgments are coordinated with specific features of dilemma cases. For instance, (DDB) may seem persuasive as long as we focus on cases where agents vacillate immediately and act without any evidence of psychological effort. To give a relatively clean example: say I offer to bet you five cents that the stranger will pull out toothpaste next, and you say, "Of course." Just a second later, someone else says they will bet you five cents that the stranger will pull out toothpaste next, and you say, "No way." That seems irrational; do you want the bet, or not? However, notice that your actions seem more acceptable as we increase the time between bets, and as we fill in the case with evidence of your being torn over whether to accept each bet. If you hesitate or fret, we are less likely to criticize you for acting differently the second time around. In fact, that is how we are apt to fill in the details of your decision about your elderly mother, the decision faced by Sartre's student, and many decisions about what career to pursue. In these decisions, it typically takes time for agents to reconsider decisions, and it typically takes effort for them to make decisions in the first place.

Our normative judgments also reflect the frequency of alleged changes of mind. (DDB) seems most persuasive when we focus on cases where agents repeatedly change how they act. Chang (1997b) points out that it is intuitively irrational for an agent to repeatedly trade between ever more lukewarm cups of tea or coffee. It is intuitively irrational for Sartre's student to dither about on train platforms, changing between trains bound for the war front and trains home to Paris. Changes that appear strategic are still another cause for censure. Say the student perpetually has misgivings about the army as his train is pulling into base camp and misgivings about his mother as his train is arriving in Paris, so that he never does anything for either side. For an epistemic analog, say that a conspiracy theorist is of several minds about the likelihood of his favorite theory. In response to a practical decision, he finally sides with some assessment of the likelihood. But as he later gets evidence that disconfirms his theory, he just happens to reconsider his prior probabilities so that his assessment of the likelihood of his theory after conditionalizing on his evidence matches his earlier assessment of its likelihood. It looks for all the world like the itinerant student is failing to act on either of his professed values, and like the conspiracy theorist is failing to update appropriately on his evidence. In other words, we are hesitant to judge that convenient patterns of action issue from permissible mental states. By contrast, we are more likely to forgive isolated shifts of allegiance.

This brings us to our second desideratum for a theory of credal dilemmas: our theory should predict the contours of our normative judgments about credal dilemma cases. According to (DDB), rejecting good pairs of bets is flatly impermissible. But our ordinary normative judgments call for a theory that is more sensitive to telling features of the contexts in which agents reject good pairs of bets, such as whether agents vacillate rapidly, easily, repeatedly, or strategically. In the next section, I 
outline such a theory. Having identified our second desideratum, we can reconceive the dialectic from Elga (2010): ordinary judgments may count in favor of theories that let agents reject good pairs of bets, rather than against them.

\section{A Theory of Credal Dilemmas}

If we accept that agents have imprecise credences, we can give a natural theory of how agents should act in credal dilemmas. An imprecise credal state is represented by a set of precise credence functions. Incommensurable values are represented by a set of value functions. ${ }^{9}$ If you have imprecise credences or incommensurable values, your mental state is represented by a set of ordered pairs, where the first element of each pair is a precise credence function and the second is a value function. Finally, any rational agent with this sort of imprecise mental state identifies with some precise mental state for purposes of action, where a precise mental state is represented by an ordered pair of a single precise credence function and a single value function.

For the purposes of this paper, we adopt two simplifying assumptions. The first is that the set of ordered pairs representing your imprecise mental state is just the Cartesian product of the set of functions representing your imprecise credal state and the set of functions representing your incommensurable values. The second is that the ordered pair representing the precise mental state that you identify with for purposes of action is a member of the set of ordered pairs representing your imprecise mental state. Hence for shorthand, we can talk about an agent identifying with some "part" of her imprecise mental state, by which we mean some precise mental state represented by a member of the set representing her imprecise mental state. $^{10}$

In a decision situation, an agent must act to maximize expected value according to the precise mental state she identifies with. But there is no rule of rationality saying that an agent cannot change which mental state she identifies with. If an agent does start to identify with another precise mental state, she must then act to maximize expected value according to that precise mental state. This is one way in which a rational agent might "change her mind," colloquially speaking. She may start to identify with another precise mental state even if she has already made decisions that did not maximize expected utility according to that state. Hence the present theory does not entail (DDB). A rational agent may identify with a precise mental state that rejects the first of a good pair of bets, and then with a state that rejects the second, whether or not she has learned anything in between.

There are multiple readings of the claim that a rational agent may identify with different precise mental states. A weak reading says that changing what precise state you identify with is compatible with being rational, i.e. that it is sometimes rationally permissible for you to change what precise state you identify with. A stronger reading says that it is always rationally permissible for you to change what precise state you identify with. The weaker claim is all I need for my argument against Elga (2010). The main point of the present paper is that susceptibility to sure losses does not itself guarantee that you are irrational. ${ }^{11}$ This point does not 
depend on any particular psychological theory about what constitutes identifying with particular credences, just as a substantive theory of moral dilemmas may not depend on any psychological theory about what constitutes identifying with particular values. There is much that can be said about the nature of credal and moral dilemmas without spelling out necessary and sufficient conditions for the psychological states that determine what is rational for agents in dilemmas of either sort.

The theory of credal dilemmas just outlined clearly satisfies the desideratum introduced in $\S 3$, namely that our theory of credal dilemmas should mirror our theory of moral dilemmas. For one thing, the theory itself gives a symmetrical treatment of imprecise credal states and incommensurable values. But more distinctively, our theory of credal dilemmas mirrors a number of extant theories of how agents should respond to moral dilemmas. For instance, it is commonly suggested that agents can respond to moral dilemmas only by virtue of being in a bifurcated state with both precise and imprecise components. Bratman (2006) says that agents in moral dilemmas adopt "an analogue of acceptance in a context, in the absence of belief" about what is valuable (712). Raz (1986) says that an agent exercises his will in order to choose between incomparable options, so that "the ability and willingness to choose does not depend on valuing the chosen option more than the rejected one" (338). Blackburn (1996) says you may "plump" for an alternative when forced to act with incommensurable values. He is clear that plumping should not involve coming to feel that your decision was correct, as admiring such behavior would amount to "admiring a lack of understanding of our past selves" (132). All of these authors are clear that agents do not respond to moral dilemmas by adopting one of the mental states they are initially torn between.

It is also common for moral theorists to endorse permissive decision rules for agents with incommensurable values. Nagel (1987) argues that agents in moral dilemmas can "proceed without further justification, but without irrationality either" (180). Raz (1997) argues that when facing moral dilemmas, we choose from among many rationally eligible options, and "we are within our rights to change our mind" (119). Hare (2010) explicitly favors a permissive decision rule for agents deciding between options that are on a par. Finally, Broome (2001) develops a permissive theory at length. According to Broome, you are required to respond to moral dilemmas in accordance with your intentions, but you are not required to have those very intentions. For example, given that Abraham intends to sacrifice Isaac, it is not the case that he should turn around and head for home after walking halfway up Mount Moriah. But nothing makes it the case that he should continue intending to sacrifice Isaac: "He has no reason not to repudiate [his intention], because he had no reason to form this particular intention in the first place. And by repudiating it he can release himself from the requirement it imposes on him. Provided he repudiates this intention, there is indeed nothing irrational about his turning back" (118). The present theory of credal dilemmas resembles Broome's theory of moral dilemmas in several respects. What you ought to do in a particular decision situation depends on a psychological fact. This fact corresponds with some precise mental state such that you must act as that state recommends according to 
standard decision theory. But no rule of rationality demands that relevant psychological facts remain constant from one decision situation to the next. Hence it is rationally permissible for Abraham to change his mind about whether to sacrifice Isaac, even if he is already halfway up the mountain.

This brief digest of moral theories highlights two very different sorts of intuitions about moral dilemmas. On the one hand, we must recognize that you cannot rationally make up your mind in more than one way at once. There is some sense in which your choice for the army is a choice against your elderly mother, and that is exactly why the former choice is so distressing. In just this sense, as Broome suggests, you repudiate an earlier action when you reject the second of a good pair of bets. On the other hand, we must recognize that when you have incommensurable values, you may bear equal allegiance to each value regardless of what actions you perform. There is some sense in which nothing you do should count as a choice against either of your values. In just this sense, as Blackburn suggests, you should remain neutral between accepting and rejecting bets that take sides on moral dilemmas, even after accepting or rejecting them. Just the same goes for agents in credal dilemmas. There is an intuitive sense in which imprecise agents make up their minds when they act, while there is an intuitive sense in which they do not. The theory I defend captures both senses. An agent identifies with a precise credal state when she acts, while multiple credal states continue to be represented by members of her representor. An agent is judged according to what some distinguished precise credence function recommends, while every member of her representor is eligible for that position of distinction.

The theory I defend gives precise interpretations of notions like making up your mind and changing your mind and having second thoughts, and so it is natural to pair my theory with psychological theories of those notions as applied to agents facing credal or moral dilemmas. In certain circumstances, changing your mind may be a common and predictable phenomenon. For instance, you may have evidence that you often second guess your decision to castle in chess, or that you hardly ever change your mind about weighty career decisions. From the third-person perspective, it is useful to reflect on what you might ordinarily take as evidence that someone did in fact change her mind about something. ${ }^{12}$ It may be that certain personality traits predispose people to change their minds more frequently, for instance. In addition, it is intuitively more likely that an agent will change her mind over the course of a few days than that she will change her mind over the course of a few seconds. If an agent hesitates or frets over some decision, it is more likely that she has imprecise credences with respect to that decision, and so more likely that she will have second thoughts about it. On the other hand, it is unlikely that an agent will have second thoughts, followed by third thoughts, followed by fourth thoughts, and so on. For most agents, relentless reconsideration is theoretically possible but generally rare, perhaps in part because deliberation itself carries nontrivial costs.

In conjunction with these simple observations, my theory meets our second desideratum, as my theory predicts that we will be more likely to judge that an agent can rationally reject good pairs of bets insofar as we have evidence that she genuinely changes her mind between bets. Since an agent is unlikely to change her mind 
immediately or without any evidence of psychological effort, we are unlikely to judge that an agent can rationally reject good pairs of bets under those circumstances. For the same reason, we are unlikely to judge that an agent is acting rationally if she is acting in ways that are permissible only if she is relentlessly reconsidering her decisions. In addition, my theory correctly predicts that our leniency increases in proportion with our evidence that agents are genuinely changing their minds. In the same way, my theory explains why we are likely to censure agents who vacillate strategically, like the itinerant student who has misgivings only at the end of long train rides, or the conspiracy theorist who has misgivings only when his favorite theory is disconfirmed. It would be an incredible coincidence if you genuinely changed which values or credences you identified with at exactly those moments where acting on such changes happened to best serve self-interested or dogmatic concerns. Hence it is incredibly unlikely that the soldier and conspiracy theorist are rational because they are genuinely changing their minds and acting to maximize expected value according to each novel mental state they identify with. There are much better explanations of their behavior available. It is most likely that the student does not actually have incommensurable values. He values selfindulgent concerns, and dithering on trains has high expected value according to that value function. It is most likely that the conspiracy theorist does not actually have imprecise credences. He is blinded by his favorite theory. His high credence in that theory is independent of his evidence, and he is failing to genuinely update on what he learns.

To be clear: it is not our intuition that agents are necessarily irrational when they change their minds rapidly or easily or repeatedly, nor does my theory predict that they are. It is a contingent fact that changes of mind are often accompanied by psychological effort, and our experience of this fact helps explain why we are disposed to judge some agents more harshly than others. In the moral dilemmas literature, some have argued that genuinely identifying with values precludes frequently switching between them. Hsieh (2007) suggests that apparent frequent switching between values may amount to adopting none of those values (77). In the same spirit, one might claim that the conspiracy theorist could not possibly be identifying with precise credal states if the conditional probabilities of those states never prompt his responses to further evidence. However, it is hasty to conclude that frequent switching between credal states is impossible. Promoting defeasible generalizations to conceptual truths risks mistaking exceptions for impossibilities. It is rare but conceivable that someone might genuinely change his mind again and again, and by coincidence thereby end up acting always in accordance with what best suits certain self-interested or dogmatic concerns. ${ }^{13}$

So far I have argued that we blame an agent for rejecting good pairs of bets when we have evidence that she did not change her mind between bets. In more limited respects, we may sometimes blame an agent for rejecting good pairs of bets even if we have evidence that she did change her mind. For instance, it could be irrational for you to move your elderly mother back and forth across the country every month, even if you changed your mind every month about whether she would most enjoy living with you or your sister. But that may just be because the cost of 
moving would eventually be high enough to outweigh the expected benefit of the move. For similar reasons, it could be irrational for a scientist to vacillate between half-finished experiments, rather than seeing some project through to its conclusion. This need not have anything to do with whether the scientist has changed her mind. The cost of setting up a new experiment may simply outweigh the relative benefit of running it. If you inherit a lab from someone, you may rationally prefer continuing some ongoing experiments even if you believe other experiments would have been slightly more fruitful.

Besides menu costs and related disadvantages, changing your mind may have less immediate or less obvious costs. For instance, certain choices produce benefits that are realized only if agents do not change their minds. The enduring nature of your longest relationships with friends, partners, or political causes may help those relationships have special features that you value. The same goes for enduring identification with precise credal states. A scientist may confirm some unlikely theory in virtue of identifying with some unusual rational response to her evidence. If her unspecific evidence does not decide between various credal states, identifying with one assessment of likelihoods may give her the resolve to pursue certain rewarding experiments. Hence practical advantages may tell decisively in favor of loyalty when it comes to identifying with a particular precise credal state. To sum up so far: there is a small arsenal of reasons why we might blame an agent for rejecting good pairs of bets, without invoking (DDB).

In addition, rejecting good pairs of bets may be lamentable, even when it is not blameworthy. For instance, certain epistemic virtues may be best expressed in the context of lasting identification with precise credal states. Just as you are not required to have any particular person as your friend, you are not required to identify with any particular precise credal state. But if you dedicate yourself in either sense, you will likely manifest honorable qualities. For instance, it requires courage to maintain a lasting relationship with a person or a theory in the face of challenges, and loyalty is a virtue distinctively expressed in such lasting relationships. Just as you are not obviously required to have lasting friendships, you are not obviously required to identify with the same precise credal state for a long time. But claims of permissibility and obligation do not exhaust our intuitive judgments. Even when an agent who often changes her mind is blameless, there may be respects in which she fails to flourish.

In some respects, my discussion of diachronic cases resembles an argument developed in Christensen (1991). Christensen evaluates a short argument for the principle of Reflection from van Fraassen (1984). The argument goes: (1) If you are willing to accept a Dutch Strategy, you are irrational. (2) If you violate Reflection, you will be willing to accept a Dutch Strategy. Therefore, (3) if you violate Reflection, you are irrational. ${ }^{14}$ Christensen objects that the argument begs the question against opponents of Reflection: "without an independent argument for the diachronic consistency of beliefs, the Dutch Strategy does not give us any reason at all to respect the principle of Reflection" (242-3). In effect, some notable alleged counterexamples to (3) are equally plausibly counterexamples to (1). For instance, suppose I falsely believe that I will be given a drug that will alter my credence in 
some proposition. Then I will violate Reflection, and I will also be willing to accept a Dutch Strategy. Hence insofar as I am rational, I constitute a counterexample to (1) just as well as to (3).

The foregoing discussion of diachronic decision cases challenges a similar argument for the following claim from Elga (2010):

(SHARP):

Perfect rationality requires one to have sharp degrees of belief.

The argument for (SHARP) goes: (1') If you are willing to reject a good pair of bets, you are irrational. (2') If you have imprecise credences, you will be willing to reject a good pair of bets. Therefore, (3') if you have imprecise credences, you are irrational. I have argued that some counterexamples to (3') are equally plausibly counterexamples to (1'), namely all those cases in which agents change their behavior after rationally changing their minds.

Christensen (1991) ends on a pessimistic note about diachronic norms of rationality: "since diachronic inconsistency is not in itself irrational or undesirable...it is hard to see any reason for thinking that a belief state which guaranteed diachronic inconsistency was something we should be concerned to avoid" (244). Briggs (2009) criticizes Christensen for claiming that we should reject diachronic norms. She points out that we need diachronic norms to distinguish rational changes of opinion from senseless or insupportable ones, and she claims that standard decision theory is just right for achieving that goal (67). I agree with Briggs that we should demand such explanations. The moral of my discussion of credal dilemmas is that standard decision theory does not obviously provide them. In particular, by generalizing to the worst case, standard decision theories assimilate cases that should be distinguished, failing to allow that agents in credal dilemmas may rationally change their minds.

\section{The Upshot for Imprecise Credences}

The foregoing arguments fall short of an argument for the claim that agents have imprecise credences. So far I have argued that Strategy B theories are preferable to Strategy A theories, i.e. that we should explain our intuitive judgments without appealing to (DDB). Standard decision theory is a Strategy A theory, while imprecise credences can be used to give a Strategy B theory. But this leaves open the possibility that there are other Strategy B alternatives to standard decision theory, including perhaps alternatives according to which rational agents do not have imprecise credences. In this section, I complete the argument. There is a token respect in which precise credences can be used to give a Strategy B theory. But that Strategy B theory essentially gives up the game to fans of imprecise credences.

Recall the example from Elga (2010) outlined in \$2. Elga says that he will offer you a good pair of bets, each of which is sanctioned by some but not all members of your representor. The circumstances are as follows: 
First I'm going to offer you Bet $A$ [on $H]$. Immediately after you decide whether to accept Bet $A$, I'm going to offer you Bet $B$. Since the bets will be offered in quick succession, you're sure that as regards the truth of $H$, your state of mind will remain exactly the same throughout the whole bet-offering process. That means: You won't get any new evidence relevant to $H$. You won't lose any evidence regarding $H$... You won't have any religious revelations, conversion experiences, or other kind of change in your opinion regarding whether $H$ is true. (4)

Elga claims that intuitively, you cannot rationally reject both bets:

(AAO):

Any perfectly rational agent who is sequentially offered bets $A$ and $B$ in the above circumstances (full disclosure in advance about the whole setup, no change of belief in $H$ during the whole process, utilities linear in dollars) will accept at least one of the bets. (4)

Elga argues that (AAO) is incompatible with viable decision theories for imprecise agents. Hence, Elga concludes, rational agents must have precise credences.

Elga provides strong circumstantial evidence that you identify with the same precise credal state when you consider Bet $A$ and Bet $B$. He stipulates that the second bet is offered "immediately," and that the bets are offered "in quick succession." He does not recognize any sense in which you hesitate or fret over your decision about either bet. From these facts, it is natural to infer that in the case described above, you do not change your mind between bets. Even more saliently, Elga stipulates that you don't have any "change in your opinion regarding whether $H$ is true" and that there is "no change of belief in $H$ during the whole process." Later Elga adds that your "state of opinion on the bet proposition will remain absolutely unchanged" (6). According to my theory, the proper response to Elga's example depends on a terminological question: does changing which precise credal state you identify with count as a "change in your opinion" for Elga? Is it possible, given Elga's description of his case, that our circumstantial evidence is misleading and you actually do change your mind between his bets, or is that ruled out by facts that Elga describes?

Suppose changing your mind counts as changing your opinion, or more generally, that the circumstances Elga describes are incompatible with your changing your mind between bets. Then my theory entails that it is impermissible to reject both bets, as Elga desires. On the other hand, suppose that the circumstantial evidence could be misleading, so that you do identify with a different precise credal state when considering Bet B after rejecting Bet A. Then we should reject (AAO), the intuition on which Elga bases his argument. In some cases, rational agents intuitively may change their minds after rejecting Bet A, in which case they may end up rejecting Bet B. Hence the central example in Elga (2010) does not immediately threaten my theory.

At this point, opponents of imprecise credences may respond by defending their own alternative to standard decision theory. In particular, they might object: "When you identify with a particular precise credal state for purposes of action, you do not 
count as having imprecise credences. Instead you have precise credences, namely the credences you identify with. In diachronic cases where agents rationally change their minds without learning, agents are simply changing which precise credences they have." To spell out a moral analog: suppose Sartre's student elects to stay with his mother, but then has a change of heart and joins the next convoy bound for England. Opponents of incommensurable values may say that it is not that Sartre's student has incommensurable values and merely changes which values he acts on. First he valued his mother more than the army, and then he valued the army more than his mother. In the same way, opponents of imprecise credences can give a Strategy B theory, as long as they say that agents in credal dilemmas can rationally change their credences without learning anything. As long as agents change their precise credences in cases where they rationally reject both bets, we can endorse non-revisionary theories about how they should act on those credences.

However, at this point, opponents of imprecise credences have essentially given up the game. According to my theory, your action is governed by the precise credal state that you "identify with." According to the alleged alternative, your action is governed by the precise credal state that you "have." This is a distinction without a difference. According to my theory, someone who does not learn anything may still rationally change which precise credal state she identifies with. According to the alleged alternative, she may rationally change which precise credal state she has. The latter claim constitutes the same radical revision of standard Bayesian doctrine as the former. Recall from $\S 1$ that imprecise credences are partly motivated by the claim that your opinions may be symmetrically related to multiple probability measures. This claim is still substantiated if a rational agent can alternately identify with precise states represented by any member of her representor, so that each is an eligible candidate for governing her action.

The opponent of imprecise credences may pursue one last line of response, namely claiming that whenever a rational agent appears to change her mind without learning, she must have learned something after all. ${ }^{15}$ If a rational agent sleeps on a hard decision and wakes up having second thoughts, she must have gotten more evidence. In reflecting on where your elderly mother would be happiest, you first believe that she should move in with you, and then you get evidence that changes your opinion.

This response has its merits, as agents may indeed fret over decisions in hopes of discovering that they have neglected relevant information. But fans of imprecise credences should remain unmoved. The same concerns that motivate imprecise credence models tell against theories that explain away all rational changes of mind. There is an important sense in which you are perpetually torn between opinions about your elderly mother, and an important sense in which your evidence might demand that you have just this sort of credal state. Insofar as there are any cases where you must act on unspecific evidence, there is no guarantee that additional evidence will make it rational for you to adopt one opinion and later adopt another. The imprecise credence theory that I have defended does justice to this conclusion, as well as our more straightforward intuition that the agents in our examples change their minds without getting more evidence. To sum up: the central 
contribution of this paper to the debate about imprecise credences is defensive. The considerations outlined in $\S 1$ offer independent motivation for ascribing imprecise credences to agents. I have argued that diachronic decision cases do not constitute an insurmountable challenge for imprecise credence fans.

In addition to defending imprecise credences against decision theoretic objections, this paper advances a more general movement, recently identified as time slice epistemology. ${ }^{16}$ According to our $\$ 5$ theory, your temporal parts may have the same evidence and yet act in ways sanctioned by different precise credal states. This claim resembles other challenges for classical principles of updating and rational action. For instance, standard updating rules fail to yield intuitive verdicts in cases where you have opinions about de se propositions, and in cases where you forget information or think you may have forgotten information. Together with cases where agents rationally change their minds, all of these cases may make us question whether your later time slices are indeed rationally constrained by the opinions and actions of your earlier time slices. Time slice epistemology constitutes a sympathetic response to this question. For the time slice epistemologist, whether you are currently rational depends only on facts about your current mental states, such as whether your actions are sanctioned by the precise credences that you currently identify with. As the movement advances, we may ultimately derive all rationality constraints from synchronic norms, replacing norms governing temporally extended agents with norms that take time slices of agents to be the fundamental subjects of epistemic evaluation.

\section{Notes}

${ }^{1}$ Canonical defenses of imprecise credences include Levi (1974), Jeffrey (1983), van Fraassen (1990), Walley (1991), Kaplan (1996), and Joyce (2010).

${ }^{2}$ For representative criticism, see Weatherson (2008), Dorr (2010), Elga (2010), and White (2010).

${ }^{3}$ For sympathetic discussion of this sort of argument, see Jeffrey (1983), Levi (1985), Walley (1991), Kaplan (1996), Joyce (2005), and Sturgeon (2010).

${ }^{4}$ Elga (2010) characterizes strict rules by analogy with the midpoint rule, but it is hard to make sense of this definition, since his midpoint rule prescribes incoherent betting behavior. Rather than adopting definitions of 'strict' and 'global' from Elga, I use these terms to refine the informal notions he introduces.

${ }^{5}$ Elga raises the same sort of concern for theories of rational action that appeal to resolute choice, such as those defended in McClennen (1990) and Gauthier (1997).

${ }^{6}$ This argument highlights assumptions made for ease of exposition: I set aside problems involving memory loss or de se updating, and I assume that standard decision theory is accompanied by the rule that you must update your credence distribution by conditionalizing it on the information you learn.

${ }^{7}$ The pragmatic argument against imprecise credences outlined here may remind the reader of classic diachronic Dutch book arguments against incoherent credences. For further discussion, see Weatherson (2008), White (2010), Joyce (2010), Williams (2014), and especially Elga (2010).

${ }^{8} \mathrm{~A}$ few brief notes about terminology: I use 'moral dilemma' without taking a stand on whether there are moral dilemmas in any technical sense. Instead I follow authors such as Foot (1983) and Railton (1996) in recognizing 'moral dilemma' as an ordinary language expression and using it with roughly its everyday meaning. Similarly, I use 'incommensurable values' for values that agents are torn between, such as those that they struggle with in ordinary moral dilemma cases. These moral dilemmas are subject-oriented rather than speaker-oriented, i.e. we should say agents face moral dilemmas in my sense when different actions are recommended by incommensurable moral values that they themselves have, as opposed to incommensurable moral values that we have. These uses of 'moral dilemma' and 
'incommensurable values' are general enough that extant discussions of both moral dilemmas and incommensurable values are sources of fruitful examples in the present context.

${ }^{9}$ It is simplest to conceive of both credence and value functions as functions on propositions, where a precise credence function measures the subjective likelihood of a proposition and a value function measures its value, though ultimately I remain neutral on details of implementation.

${ }^{10}$ This shorthand does not commit us to any controversial claims about whether imprecise mental states are built from precise mental states in any deep metaphysical sense, as criticized in Sturgeon (2009). For further discussion of these simplifying assumptions, see $\S 5$ of Moss (2013), where I motivate and describe some ways of revising both assumptions.

${ }^{11}$ This point is compatible with the claim that certain psychological states rationally preclude changes of mind, as argued by Holton (1999), (2004); Bratman (2000); and others. The important claim for my purposes is that imprecise agents are not always rationally required to enter such psychological states, and in particular, that merely acting in accordance with some representor member does not entail entering such a state. For present purposes, I set aside further discussion of possible defeaters of the rational permissibility of mind changing.

${ }^{12}$ Here I do not mean conclusive evidence, but rather any claim that counts in favor of the hypothesis that some change of mind occurred.

${ }^{13}$ Throughout this discussion, I have assumed that we can distinguish identifying with concerns from merely acting in accordance with them. The literature on rule-following demonstrates that it is notoriously difficult to spell out this sort of distinction precisely. I expect that puzzles about following rules are a fortiori puzzles about following decision rules. For present purposes, I rely on our intuitive grasp of the latter and set aside general worries about rule-following.

${ }^{14}$ For a careful definition of 'Dutch Strategy' and further background details, see Teller (1976), van Fraassen (1984), Christensen (1991), and Hájek (2008).

${ }^{15}$ To be exact: your precise credal state must have undergone a rationally permissible change, i.e. a change that reflects some change in your evidential situation. As we have been setting aside cases involving memory loss and de se updating, we may assume that such rational credal changes will involve your coming to have more evidence, as opposed to strictly less evidence.

${ }^{16}$ For further discussion, see Moss (2013) and Hedden (2013a), (2013b).

\section{References}

Blackburn, Simon. (1996). "Dilemmas: Dithering, Plumping, and Grief." In Mason (1996), 127-39. Bratman, Michael. (2000). "Reflection, Planning, and Temporally Extended Agency." Philosophical Review, vol. 109 (1): 35-61.

. (2006). "Thinking How to Live and the Restriction Problem." Philosophy and Phenomenological Research, vol. 72 (3): 707-13.

Briggs, Rachael. (2009). "Distorted Reflection.” Philosophical Review, vol. 118 (1): 59-85.

Broome, John. (1999). Ethics out of Economics. Cambridge University Press, Cambridge.

(2001). "Are Intentions Reasons? And How Should We Cope With Incommensurable Values?"

In Practical Rationality and Preference: Essays for David Gauthier, Christopher Morris \& Arthur Ripstein, editors, 98-120. Cambridge University Press, Cambridge.

Chang, Ruth, editor. (1997a). Incommensurability, Incomparability, and Practical Reason. Harvard University Press, Cambridge.

Chang, Ruth. (1997b). "Introduction." In Chang (1997a), 1-34.

Christensen, David. (1991). "Clever Bookies and Coherent Beliefs." Philosophical Review, vol. 100 (2): 229-47.

Dorr, Cian. (2010). "The Eternal Coin: A Puzzle About Self-Locating Conditional Credence.” Philosophical Perspectives, vol. 24 (1): 189-205.

Elga, Adam. (2010). "Subjective Probabilities Should Be Sharp." Philosophers' Imprint, vol. 10 (5): 1-11.

Foot, Philippa. (1983). "Moral Realism and Moral Dilemma." Journal of Philosophy, vol. 80 (7): 379-98.

van Fraassen, Bas. (1984). "Belief and the Will.” Journal of Philosophy, vol. 81 (5): 235-56.

(1990). "Figures in a Probability Landscape." In Truth or Consequences: Essays in Honor of Nuel Belnap, J.M. Dunn \& A. Gupta, editors, 345-56. Kluwer, Dordrecht. 
Gauthier, David. (1997). "Resolute Choice and Rational Deliberation: A Critique and a Defense." Noûs, vol. 31 (1): 1-25.

Gendler, Tamar Szabó \& John Hawthorne, editors. (2010). Oxford Studies in Epistemology, vol. 3. Oxford University Press, Oxford.

Gowans, Christopher, editor. (1987). Moral Dilemmas. Oxford University Press, New York.

Hájek, Alan. (2008). "Dutch Book Arguments." In The Oxford Handbook of Rational and Social Choice, Paul Anand, Prasanta Pattanaik \& Clemens Puppe, editors, 173-95. Oxford University Press, Oxford.

Hare, Caspar. (2010). "Take the Sugar." Analysis, vol. 70 (2): 237-47.

Hedden, Brian. (2013a). "Options and Diachronic Tragedy." Philosophy and Phenomenological Research. Article published online first. DOI: 10.1111/phpr.12048.

(2013b). "Time-Slice Rationality.” Ms., Dept. of Philosophy, Oxford University. Forthcoming in Mind.

Holton, Richard. (1999). "Intention and Weakness of Will." Journal of Philosophy, vol. 96 (5): 241-62. (2004). "Rational Resolve." Philosophical Review, vol. 113 (4): 507-35.

Hsieh, Nien-hê. (2007). "Is Incomparability a Problem for Anyone?" Economics and Philosophy, vol. 23 (1): $65-80$.

Jeffrey, Richard C. (1983). "Bayesianism With a Human Face." In Testing Scientific Theories, John Earman, editor, 133-56. University of Minnesota Press, Minneapolis.

Joyce, James. (2005). "How Probabilities Reflect Evidence." Philosophical Perspectives, vol. 19 (1): 15378.

(2010). "A Defense of Imprecise Credences in Inference and Decision Making." Philosophical Perspectives, vol. 24 (1): 281-323.

Kaplan, Mark. (1996). Decision Theory as Philosophy. Cambridge University Press, Cambridge.

Levi, Isaac. (1974). "On Indeterminate Probabilities.” Journal of Philosophy, vol. 71 (13): 391-418.

(1985). "Imprecision and Indeterminacy in Probability Judgment." Philosophy of Science, vol. 52 (3): 390-409.

Mason, H. E., editor. (1996). Moral Dilemmas and Moral Theory. Oxford University Press, New York.

McClennen, Edward. (1990). Rationality and Dynamic Choice: Foundational Explorations. Cambridge University Press, Cambridge.

Moss, Sarah. (2013). "Time Slice Epistemology and Action Under Indeterminacy." Ms., Department of Philosophy, University of Michigan. Forthcoming in Oxford Studies in Epistemology, vol. 5. Oxford University Press, Oxford.

Nagel, Thomas. (1987). "The Fragmentation of Value.” In Gowans (1987), 174-87.

Railton, Peter. (1996). "The Diversity of Moral Dilemma.” In Mason (1996), 140-66.

Raz, Joseph. (1986). The Morality of Freedom. Oxford University Press, New York. (1997). "Incommensurability and Agency." In Chang (1997a), 110-28.

Sartre, Jean-Paul. (1946). "The Humanism of Existentialism.” In Jean-Paul Sartre: Essays in Existentialism, Wade Baskin, editor, 31-62. Carol Publishing Group, New York.

Sturgeon, Scott. (2009). "Belief, Reason, and Logic." Royal Institute of Philosophy Supplement, vol. 84 (64): 89-100.

(2010). "Confidence and Coarse-Grained Attitudes." In Gendler \& Hawthorne (2010), 126-49.

Teller, Paul. (1976). "Conditionalization, Observation, and Change of Preference." In Foundations of Probability Theory, Statistical Inference, and Statistical Theories of Science, W. Harper \& C.A. Hooker, editors, 205-53. D. Reidel, Dordrecht.

Walley, Peter. (1991). Statistical Reasoning with Imprecise Probabilities. Chapman and Hall, London.

Weatherson, Brian. (2008). "Decision Making with Imprecise Probabilities." Ms., Dept. of Philosophy, University of Michigan.

White, Roger. (2010). "Evidential Symmetry and Mushy Credence." In Gendler \& Hawthorne (2010), $161-86$.

Williams, Bernard. (1965). "Ethical Consistency." In Gowans (1987), 115-37. Originally published in Proceedings of the Aristotelian Society 39, 103-24.

Williams, J. Robert G. (2014). "Decision Making Under Indeterminacy.” Philosophers' Imprint, vol. 14 (4): $1-34$. 